\title{
From "leaky gut" to impaired glia-neuron communication in depression
}

\section{Authors:}

Leszek Rudzki ${ }^{1}$ ORCID iD: https://orcid.org/0000-0001-5605-0494

Michael Maes ${ }^{2-4}$ ORCID iD: https://orcid.org/0000-0002-2012-871X

1. The Charleston Centre, Paisley, United Kingdom

2. Department of Psychiatry, Faculty of Medicine, Chulalongkorn University, Bangkok, Thailand

3. Department of Psychiatry, Medical University of Plovdiv, Plovdiv, Bulgaria

4. IMPACT Strategic Research Center, Deakin University, Geelong, Australia

\section{Corresponding author:}

Leszek Rudzki MD, PhD

rudzki.1@gmail.com

The Charleston Centre, Paisley, United Kingdom

49 Neilston Road, Paisley PA2 6LY, United Kingdom

Keywords: depression, leaky gut, microbiota, cytokines, neuroimmunomodulation, oxidative stress, glia, blood-brain barrier, LPS, TLR 


\begin{abstract}
In the last three decades, the robust scientific data emerged, demonstrating that the immuneinflammatory response is a fundamental component of the pathophysiology of major depressive disorder (MDD). Psychological stress and various inflammatory comorbidities contribute to such immune activation. Still, this is not uncommon that patients with depression do not have defined inflammatory comorbidities, and alternative mechanisms of immune activation need to take place. The gastrointestinal (GI) tract, along with gut-associated lymphoid tissue (GALT), constitutes the largest lymphatic organ in the human body and forms the biggest surface of contact with the external environment. It is also the most significant source of bacterial and food-derived antigenic material. There is a broad range of reciprocal interactions between the GI tract, intestinal microbiota, increased intestinal permeability, activation of immune-inflammatory response, and the CNS that has crucial implications in brain function and mental health. This intercommunication takes place within the microbiota-gut-immune-glia (MGIG) axis, and glial cells are the main orchestrator of this communication. A broad range of factors, including psychological stress, inflammation, dysbiosis and other, may compromise the permeability of this barrier. This leads to excessive bacterial translocation and the excessive influx of food-derived antigenic material that contributes to activation of the immuneinflammatory response and depressive psychopathology. This chapter summarizes the role of increased intestinal permeability in MDD and mechanisms of how the "leaky gut" may contribute to immuneinflammatory response in this disorder.
\end{abstract}




\section{Introduction}

For over four decades, the monoaminergic hypothesis mostly defined our understanding of major depressive disorder (MDD). This hypothesis postulated that deficits in certain neurotransmitters, including serotonin (5-HT), noradrenaline, and dopamine, contribute to MDD symptomatology and that antidepressant treatment improves depressive symptoms due to the restoration of the appropriate neurotransmission. However, in the last two decades, a piece of robust scientific evidence emerged indicating that MDD is accompanied by the low-grade immune-inflammatory response, which has a crucial role in the pathophysiology of this disorder. Consequently, various immune hypotheses of this disorder emerged, including the macrophage hypothesis of depression (1), the monocyte-T-lymphocyte hypothesis (2), a neurodegeneration hypothesis (3), the cytokine hypothesis (4) the glutamate hypothesis (5), "leaky gut" hypothesis $(6,7)$, or depression as a glial-based synaptic dysfunction (8), to name a few. Those hypotheses reciprocally complement each other and represent a continuum of evolving understanding of depression. It also became clear that the monoaminergic paradigm is just a part of the much bigger and intriguingly complicated psycho-neuro-immunological picture.

Some of the crucial aspects of immune-inflammatory response in MDD include increased levels of pro-inflammatory cytokines i.e., IL-1 $\beta$, TNF- $\alpha$, IL-6 $(4,9)$, activation of oxidative and nitrosative stress (O\&NS) and decreased levels of crucial antioxidants and total antioxidant capacity in depressed patients (10-13). Also, it has been demonstrated that O\&NS may generate neoepitopes with subsequent autoimmunity in depressed patients (14). Furthermore, MDD is accompanied by abnormalities in the metabolism of tryptophan and its catabolites in the kynurenine pathway (TRYCATs / kynurenines) what manifests with the decreased amount of tryptophan available for conversion to 5-HT and increased conversion of tryptophan to TRYCATs. Those kynurenines may exert neurotoxic, pro-oxidative effects on the CNS, and increase glutamate neurotransmission (3, 15-18). Moreover, MDD is often comorbid with various inflammatory and autoimmune disorders, which could contribute to the activation of the inflammatory response in MDD. Those, for instance, include inflammatory bowel diseases (IBD) i.e., Crohn's disease, ulcerative colitis or irritable bowel syndrome (IBS), further, rheumatoid arthritis, multiple sclerosis (MS), coronary artery disease, chronic obstructive pulmonary disease (COPD), HIV infection (human immunodeficiency virus), Alzheimer's disease and other, and their comorbidity reciprocally worsens the course and prognosis. Still, this is not uncommon that patients with MDD do not have defined inflammatory comorbidities, and alternative mechanisms of immune activation in this disorder need to take place.

One of the major contributors to activation of immune-inflammatory response is psychological stress, which with the involvement of hypothalamic-pituitary-adrenal (HPA) axis and the activation of the sympathetic nervous system (SNS), upregulates the expression of nuclear factor kappa beta (NF$\kappa \mathrm{B})$ in mononuclear cells what results with an increase of pro-inflammatory cytokines release (19-21). Moreover, catecholamines induce activation of microglia, the release of pro-inflammatory cytokines in 
the periphery and within the CNS, and increase the trafficking of macrophages to the CNS. Psychological stress also upregulates the TLR-4 pathway and exacerbates response to bacterial LPS (21-24).

Another crucial element that links the effects of psychological stress and immunity is the gastrointestinal (GI) tract with the gut-associated lymphoid tissue (GALT). GI tract, along with GALT, constitutes the largest lymphatic organ in the human body, and it is responsible for the production of $70-80 \%$ of immune cells. Given that, in the last decade, there is a growing interest in reciprocal interactions between the GI tract, intestinal microbiota, increased intestinal permeability, activation of immune-inflammatory response, and the CNS. This intercommunication takes place within the microbiota-gut-brain axis or recently proposed the microbiota-gut-immune-glia (MGIG) axis (25), since glial cells are the main orchestrator of the immune response within CNS, and mediate the central response to the systemic inflammation. GI tract forms the biggest surface of contact of the human body with the external environment, and it is the most significant source of bacterial and food-derived antigenic material.

Bacterial LPS/endotoxin, which is a cell wall component of Gram-negative bacteria, along with other bacterial-derived antigenic material including flagellins, lipoproteins, peptidoglycans belong to so-called pathogen-associated molecular patterns (PAMPs) and are recognized by pattern recognition receptors (PRRs) including Toll-like transmembrane receptors (TLRs). TLRs constitute broad antigen sensing "machinery" and, of particular interest, TLR4 are responsible for recognizing bacterial LPS. Those receptors are expressed on various immune and non-immune cells both in the periphery and within the CNS, such as dendritic cells, lymphocytes, monocytes, macrophages, granulocytes, astrocytes, microglia, oligodendrocytes and tissues including intestinal tissue (26). LPS can also activate receptors for advanced glycation end products (RAGE) which can lead to endothelial hyperpermeability (27). The second group of gut-derived antigens, which could play a significant part in the immune-inflammatory mechanism in MDD are food-derived antigens.

Permeability of the intestinal barrier is the main determinant of the extent of bacterial translocation from the intestinal lumen and subsequent activation of TLR4 receptors. Importantly, this barrier's permeability may be compromised by a broad range of factors, including psychological stress with the involvement of HPA axis activation and corticotropin-releasing hormone (CRH)-mediated mast cells activation (Fig.1) (28-34). Also, psychological stress may contribute to increased intestinal permeability via activation of SNS and activation of $\beta 2$-adrenergic receptors expressed on epithelial cells $(33,35,36)$. Moreover, factors compromising gut barrier include pro-inflammatory cytokines such

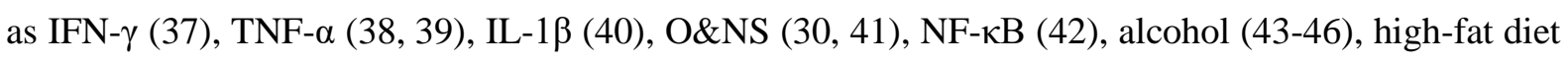
(47) and obesity (48), traumatic brain injury (49), food additives and pesticides (50-55), prolonged strenuous exercise $(56,57)$, heat stress $(58)$, infections $(59,60)$, some medications for instance, antibiotics (61-64) and non-steroidal anti-inflammatory drugs (NSAID) $(65,66)$. Finally, since gut microbes are the "natural guardians" and modulators of this barrier's integrity, abnormalities in their 
composition, including dysbiosis and small intestine bacterial overgrowth (SIBO), contribute to increased intestinal permeability $(46,67,68)$. Importantly, MDD is accompanied by changes in the intestinal microbiota composition (69-73), and dysbiosis was also demonstrated in other psychiatric disorders, including chronic fatigue syndrome (CFS) (74), schizophrenia and bipolar disorder $(75,76)$, autism (77-81) and alcoholism (46). Additionally, psychological stress has a detrimental influence on intestinal microbiota composition what has a negative impact on mucosal immunity and results with an increase of parameters of peripheral and central inflammation (82-84). In view of the above, growing scientific data demonstrates that various psychiatric disorders including $\operatorname{MDD}(6,7,14,76,85-87)$, schizophrenia (88-90), bipolar disorder (76), CFS (91, 92), autism (93-95), alcohol dependence (44-46) are accompanied by increased intestinal permeability. Furthermore, numerous inflammatory disorders, which are comorbid with MDD, including celiac disease, IBD, IBS, rheumatoid arthritis, ankylosing spondylitis, MS, type 1 and type 2 diabetes, asthma, atopic eczema, are also accompanied by increased intestinal permeability (96-99).

Finally, glial cells, which are non-neuronal and most abundant cell types in the CNS, play a crucial role in the brain's immune response to both systemic and central inflammation, and reciprocally cross-talk with neurons. Those cells include astrocytes, microglia, oligodendrocytes, ependymal cells, Schwann cells, and satellite cells. In particular, astrocytes, microglia, and oligodendrocytes are mainly involved in psychiatric manifestations of gut-derived immune-inflammatory response, and various glial abnormalities accompany MDD. It is noteworthy that these cells express TLR4 receptors for endotoxin, and subsequently, bacterial translocation influenced their functions and structure. Astrocytes are involved in different metabolic processes, including ion and fluids balance and energetic metabolism. Those cells produce a broad range of gliotransmitters, including glutamate, adenosine triphosphate (ATP), D-serine, and are the source of different neurotrophic factors involved in neurotransmission and synaptic plasticity. Astrocytes play a significant part in the regulation of glutamate and gammaaminobutyric acid (GABA) neurotransmission and are responsible for the reuptake of about $90 \%$ of the glutamate. Subsequently, their dysfunction leads to glutamate excess and inappropriate balance between excitatory and inhibitory neurotransmission (Fig.1). Astrocytes also have a pivotal role in the bloodbrain-barrier (BBB) function and its permeability (100). Abnormalities in astrocytes function and structure, namely astrogliosis, accompanies MDD, and depressed patients have decreased number and density of those cells in brain regions involved in MDD such as the hippocampus, amygdala and prefrontal cortex (101-103). Also, psychological stress has a negative influence on the structure and functions of astrocytes and microglia (104). Consequently, antidepressant treatment, including antidepressant medication, lithium, and electroconvulsive therapy (ECT) has a beneficial influence on the structure and functions of astrocytes $(101,105)$.

Microglia is another group of glial cells involved in MDD. Those brain resident-macrophages are mainly participating in immune regulation, and they are "the first line" immune defense of the CNS. Those cells are equipped with a broad plethora of pro-inflammatory mechanisms, including cytokines, 
chemokines, nitric oxide (NO), prostaglandins, pro-oxidative kynurenines, such as 3hydroxykynurenine (3OHKYN) and quinolinic acid (QUIN). These immune mechanisms can be lifesaving, but when excessively and chronically triggered, can be detrimental to brain functions and mental health. Microglia release neurotrophins, including brain-derived neurotrophic factor (BDNF) and neurotransmitters, i.e., ATP and glutamate, and are involved in synaptogenesis, synaptic pruning, sampling, and elimination. Interestingly, glutamate influences microglial chemotaxis, and microglia migrate towards the origin of increased glutamate release (106). Consequently, abnormalities in microglia proportions (primed v.s resting cells), functions, and morphology, namely microgliopathy, were demonstrated in MDD and suicidality $(107,108)$. It was also shown that antidepressant treatment attenuates microglial activation, including the release of glutamate and pro-inflammatory cytokines (109-111). Moreover, psychological stress has a negative impact on microglia morphology, particularly in brain areas related to MDD and anxiety, such as the hippocampus, prefrontal cortex, amygdala, hypothalamus, and nucleus accumbens (112).

Last but not least are oligodendrocytes, which are mainly involved in myelin formation. Astrocytes and microglia profoundly influence these glial cells. Pro-inflammatory cytokines, O\&NS, and glutamate may compromise functions of oligodendrocytes, particularly myelin formation and abnormalities in oligodendrocytes function and myelin formation were demonstrated in MDD (113-115).

In this chapter will summarise the role of increased intestinal permeability in major depression and mechanisms of how the "leaky gut" may contribute to immune-inflammatory response in this disorder.

\section{The evidence of increased intestinal permeability in depression}

\section{Increased intestinal permeability to bacterial antigens}

It is becoming increasingly evident that MDD is accompanied by increased intestinal permeability, which could contribute to the low-grade immune-inflammatory response in patients with MDD (Fig.1). The first evidence of the "leaky gut" in depression was demonstrated in two consecutive studies, which revealed that MDD patients had increased serum levels of immunoglobulins A (IgA) and M (IgM) against LPS of enteric commensal bacteria. Additionally, patients with chronic depression (duration > two years) had higher IgM responses compared to non-chronically depressed patients (6, 7). It was also demonstrated that patients with melancholic versus non-melancholic depression had higher IgA to gut commensal Citrobacter Koseri, and Hamilton Depression Rating Scale (HAM-D) score was significantly associated with IgA to Citrobacter Koseri (76). Moreover, IgG to oxidized LDL (oxLDL) was significantly associated with increased bacterial translocation what is consistent with earlier results, which demonstrated that increased translocation of gut microbes might drive oxidative and nitrosative stress and autoimmune responses against O\&NS generated neoepitopes in depressed 
patients $(14,76)$. Another research demonstrated increased plasma levels of bacterial LPS along with increased levels of zonulin and intestinal fatty acid-binding protein-2 (FABP2) in patients with anxiety and depressive symptoms (85). Zonulin is a regulator of intestinal permeability, and FABP2 is a marker of the defective intestinal barrier. It should be noted that increased zonulin levels were also revealed in various inflammatory and autoimmune disorders, which are often comorbid with MDD (116). In the same study, patients with depression and anxiety presented with gut dysbiosis and their abnormal intestinal bacterial flora composition was correlated with levels of LPS, zonulin, and FABP2 what indicates that dysbiosis may contribute to increased intestinal permeability in MDD. In another study, patients with MDD had significantly elevated plasma level of 16S ribosomal RNA (rRNA) subunit (16S rDNA) of intestinal microbiota, and this parameter is an indicator of bacterial translocation (117). Furthermore, patients had increased plasma expression of TLR-4 RNA and protein and increased expression NF-kb RNA, and increased concentration of IL-6. Strikingly, sixteen weeks of cognitivebehavioral therapy (CBT) significantly decreased expressions of TLR-4 RNA and protein, NF-kb RNA, and reduced level of $16 \mathrm{~S}$ rDNA what indicates that CBT contributed to decrease of intestinal permeability. Additionally, greater decrease in pro-inflammatory parameters during CBT was associated with more pronounced clinical improvement in Hamilton Depression Rating Scale (HAMD). Using another approach of intestinal barrier assessment, namely measurement of the lactulose/mannitol ratio (LMR), a positive association between intestinal permeability and depressive symptoms severity in unmediated adolescents, particularly neurovegetative symptoms, was demonstrated (86). Authors also revealed the association between sympathetic nervous system (SNS) activity and the gut permeability and suggested that intestinal permeability could mediate the association between MDD symptoms and the activity of SNS.

\section{Increased intestinal permeability to food-derived antigens}

Another aspect of "leaky gut" in MDD is an increased gut permeability to food-derived antigens (Fig.1). It was proposed that increased intestinal permeability to food antigens with subsequent type III hypersensitivity and formation of $\mathrm{IgG}$ complexes may contribute to low-grade immune-inflammatory response in MDD $(118,119)$. Recently Tao et al. demonstrated that depressed adolescents had a higher rate of serum food-specific IgG that was accompanied by increased serum levels of histamine, S100 calcium-binding protein B (S100B), and homocysteine (120). S100B is considered as a marker of increased permeability of BBB and is primarily expressed in astrocytes. Authors concluded that IgGmediated type III hypersensitivity against food antigens could be the principal cause of increased histamine level, which in turn contributed to increased BBB permeability in depressed patients. It is worth noting that increased histamine release from i.e., mast cells is not exclusively mediated by IgE and that binding of $\mathrm{IgG}$ with receptors for the $\mathrm{Fc}$ portion of immunoglobulins (FcR), for instance, Fc $\gamma$ RIII, also contributes to histamine release (121). Another study revealed that when depressed 
patients were tested for IgG levels against 39 selected food antigens, patients had significantly higher serum total $\operatorname{IgG}$ and $\mathrm{IgG}$ against celery, garlic and gluten compared to the control group (122). It was also previously demonstrated that IgG concertation against 5 out of 44 food products $(11.36 \%)$ positively correlated with the length of depressive episodes (119). Those results could indicate that the longer duration of depressive symptoms could be related to more pronounced intestinal permeability and subsequent inflammatory response. This seems consistent with the previous report that patients with chronic depression had significantly higher IgM responses against commensal bacteria compared to healthy controls (7). Still, two scenarios seem plausible regarding the activation of low-grade immune-inflammatory response and "leaky gut" in depression. On the one hand, activation of the immune-inflammatory response can be secondary to increased intestinal permeability. On the other hand, increased intestinal permeability can be secondary to inflammatory factors i.e., activation of HPA axis, pro-inflammatory cytokines, Nf-kb, and O\&NS which all are the essence of the immune response in various inflammatory disorders.

To summarise, the current literature demonstrates that increased intestinal permeability to bacterial and food-derived antigens accompanies MDD. However, what are the immune consequences and mechanisms which may lead to gut-derived psychiatric manifestations, particularly depressive symptomatology?

\section{Crossing the barriers beyond the brain's privileged immunity}

\section{Central consequences of peripherally LPS-induced immune-inflammatory response}

There are various mechanisms of how bacterial LPS contribute to the activation of the immuneinflammatory response both in the periphery and in the CNS (Fig.1). It is, however, important to emphasize that activation of the immune-inflammatory response due to an increase of LPS level in the circulation is not restricted to the periphery but also results with activation of inflammatory response within the CNS and glial cells are primarily involved in this process. Therefore, it is well established that peripheral LPS challenge leads to sickness behaviors, depressed mood, anxiety, and a decline in the cognitive functions both in humans and animals $(123,124)$. Peripheral LPS administration also led to robust activation of brain microglia in humans what was assessed using PET brain imaging (125). This was accompanied by an elevation of circulating cytokines TNF- $\alpha$, IL-6, IL-8, and IL-10 and sickness behaviors, including fatigue and reduction in social interest. In addition, peripheral stimulation with LPS induced microglial proliferation in the circumventricular organs, hypothalamus, limbic system and medulla oblongata (126). Consequently, it was demonstrated that peripheral administration of LPS led to increased expression of cortical and hippocampal IL-1 $\beta$, TNF- $\alpha$, GFAP and iNOS. This was accompanied by decreased expression of BDNF and depressive-type behaviors in laboratory animals. Inhibition of astrocytes resulted in a decrease in above mentioned neuroinflammatory 
parameters, reversed LPS-induced decreased in BDNF and attenuated depressive-like behaviors (127). Consistently, antidepressant treatment with tricyclic antidepressants (TCA), selective serotonin reuptake inhibitors (SSRIs), transcranial magnetic stimulation and electroconvulsive therapy had a beneficial effect on number and morphology of those glial cells (101). Similarly, TCA and SSRIs inhibited LPS-induced depressive-like behaviors and IL-6 release in laboratory animals (109), attenuated the release of TNF- $\alpha$, NO (110), and glutamate, and D-serine release by activated microglia (111). Also, lithium prevented LPS-induced activation of astrocytes, TLR4 expression and proinflammatory cytokine production and this mood stabilizer also has a strong antidepressant and antisuicidal properties (105). Furthermore, minocycline, which is a tetracycline antibiotic with antidepressant properties, has known anti-neuroinflammatory and microglia modulatory properties (128). In LPS-stimulated brain microglial cells, minocycline blocked the secretion of pro-inflammatory cytokines. In the second part of this study minocycline reduced mRNA levels of IL-1 $\beta$, IL-6, and IDO in the cortex and hippocampus of laboratory animals, which were peripherally stimulated with LPS. This was accompanied by a reduction in anhedonia and sickness behaviors (129). Furthermore, LPS have a detrimental influence on oligodendrocytes maturation and myelination (130).

Bacterial LPS after translocation binds to PAMP, such as TLR4 and activate MyD88-dependent and MyD88-independent pathways of the innate immune response through NF-kB signaling what leads to increased release of pro-inflammatory cytokines including IL- $1 \mathrm{~b}$, TNF- $\alpha$, IL-6 and type I interferons (IFNs). Endotoxin can also activate RAGE what can lead to endothelial hyperpermeability (27). Moreover, this bacterial molecule can activate the classical component system what may lead to neuropathology, including dopaminergic neurons loss $(131,132)$.

LPS-induced release of pro-inflammatory cytokines can influence brain and behavior via humoral, neural and cellular pathways (133). The humoral pathway includes passage of cytokines through more permeable areas of BBB such as choroid plexus and circumventricular organs, activation of BBB endothelium and subsequent release of second messengers including prostaglandins and nitric oxide which further activate inflammatory cascade within the brain parenchyma. Moreover, some cytokines do have specific transport molecules in the endothelium, which allows for active transport via BBB. Cytokines can also act through neural route, for example, by activating afferent fibers of the vagal nerve. Furthermore, cytokines contribute to the entry to the brain parenchyma of monocytes activated in the periphery. During peripheral inflammation, cerebral microglia recruit monocytes into the brain via the release of cerebral monocyte chemoattractant protein (MCP)-1 and increased numbers of circulating CCR2-expressing monocytes. Also, peripheral TNF- $\alpha$ is required to stimulate microglia to produce chemokine MCP-1/CCL2 $(133,134)$. It was also recently demonstrated that peripheral LPS challenge results with the influx of leucocytes to the brain parenchyma. Respectively, prolonged, repeated exposure to peripheral LPS resulted in microglia activation and increased expression of various chemokines, which attracted neutrophils, monocytes to the brain parenchyma. This led to increased BBB permeability and transient recruitment of neutrophils and monocytes and sustained infiltration of 
monocytes, T-cells, NK cells and NK T cells to the brain parenchyma. Interestingly, following consecutive challenges, peripheral tolerance to LPS developed, which manifested with not as pronounced inflammatory response in the periphery, however in the brain, the inflammatory process progressed and manifested with increased transcription of inflammatory cytokines and chemokines (135).

\section{"The TLRs perspective"}

There is a broad presence of the TLR4 microbe sensing "machinery" in different brain cells, including astrocytes, microglia, oligodendrocytes, neurons, perivascular macrophage, endothelium, meninges and circumventricular organs (136). Those receptors are also expressed on dendritic cells, lymphocytes, monocytes, granulocytes, and tissues, including intestinal tissue (26). Such a broad expression of PAMPs within-CNS and periphery surely have to serve its purpose and indicate that brain tissue is well familiar with the endotoxin molecule (137). It is even more so in MDD and various neurodegenerative disorders. However, the latter are beyond the scope of this chapter. When it comes to depression, post mortem study revealed over-expression of TLR3 and TLR4 in the dorsolateral prefrontal cortex of depressed suicide victims and depressed non-suicide subjects, compared with controls (138). Animal studies demonstrated that exposure to LPS $(139,140)$ and psychological stress (141) enhances expression of TLR4 and higher expression of TLR3, 4, 5, and 7 mRNA was demonstrated in peripheral blood of depressed patients (137). TLR4 mRNA expression was associated with the severity of MDD measured with the Hamilton Depression Rating Scale (HAMD-17). Moreover, it was demonstrated that four weeks of antidepressant treatment of MDD patients significantly decreased expression of TLRs (1-9) in peripheral blood mononuclear cells (PBMCs) (142) and lithium inhibited LPS-induced astrocytes activation via inhibition of TLR4 expression (105). Also, sixteen weeks of cognitive CBT significantly decreased the expressions of TLR-4 RNA and protein, which was accompanied by the improvement of intestinal barrier function (117).

\section{LPS and kynurenines}

Another essential element in this depression-related inflammatory puzzle is the kynurenine pathway. Bacterial lipopolysaccharides, O\&NS and pro-inflammatory cytokines, including IFN $\gamma$, IL$1 \beta$, IL- 6 , TNF- $\alpha$, and cortisol, can activate the first step enzymes in the kynurenine pathway particularly indoleamine 2,3-dioxygenase (IDO) and tryptophan 2,3-dioxygenase (TDO) (Fig.1). The former is expressed in antigen-presenting cells during immune reactions, and TDO is mostly expressed in the liver and neurons. Those enzymes are involved in the conversion of tryptophan (5-HT and melatonin precursor) to kynurenine and its further catabolites (TRYCATs) what subsequently decreases the amount of tryptophan available for conversion to 5-HT. TRYCATs perform numerous critical physiological roles, including immunomodulatory functions however, their excess may have an adverse 
effect on the CNS functions. For instance, quinolinic acid (QUIN) is an N-methyl-D-aspartate (NMDA) receptor agonist and has neurotoxic activity due to stimulation of synaptosomal glutamate release and inhibition of its reuptake by astrocytes. This results in an increase in its concentration in the synapse and excessive stimulation of the NMDA receptors $(143,144)$, and increased oxidative stress (145). This is particularly important in the context of glutamate hypothesis of depression where due to dysfunction and decreased number of astrocytes, there is not sufficient reuptake of glutamate what leads to an imbalance between glutamate and GABA neurotransmission. Therefore, it was demonstrated that activation of microglia resulted in IDO activation, the elevation of detrimental kynurenines, and an increase in glutamate neurotransmission (107). This also resulted in inhibition of the brain's tropic factors synthesis, including BDNF, and in decreased neurogenesis.

Another kynurenine metabolite - 3-hydroxykynurenine (3HKYN) has neurotoxic, neuroapoptotic and pro-oxidative effects and is further metabolized to pro-oxidative 3hydroxyanthranilic acid (3HAA). In contrast, kynurenic acid (KYNA) is an NMDA receptor antagonist and modulates acetylcholine 7 alpha nicotinic receptor $(\alpha 7-\mathrm{nACh})$ functions, and it is believed that KYNA counteracts the neurotoxic effects of the above-mentioned QUIN (146, 147). Accordingly, Myint and Kim proposed the neurodegeneration hypothesis of MDD and demonstrated that an imbalance between neuroprotective and neurodegenerative metabolites in the kynurenine pathway contributes to $\operatorname{MDD}(3,15)$. Still, it is important to keep in mind that despite "neuroprotective" effects of KYNA and its antagonism to QUIN, those kynurenines, when in excess, contribute to neurodegeneration and cognitive decline, in schizophrenia, bipolar disorder, Alzheimer's, Parkinson's and Huntington's diseases, dementia related to HIV infection, amyotrophic lateral sclerosis (ALS), postsurgical cognitive decline and other (148-150). The negative impact of QUIN and KYNA on cognitive functions is mainly due to their ability to modulate glutamate and acetylcholine neurotransmission (148). It is noteworthy that the brain's glial cells are the site of TRYCATs metabolism and tryptophan, and kynurenine after crossing BBB became substrates for further TRYCATs synthesis within CNS. More precisely, the "neuroprotective" KYNA synthesizing branch is located in astrocytes and neurotoxic QUIN synthesizing branch is compartmentalized in microglia. Peripheral LPS challenge influences the metabolism of TRYCATs in the brain and in the periphery. LPS challenge increased kynurenine/tryptophan ratio both in the periphery and in the CNS. It resulted in increased expression of pro-inflammatory cytokines IL- $1 \beta$, TNF- $\alpha$, and IL- 6 in the hippocampus, amygdala, and striatum, and was accompanied by an increase of neuroinflammatory glial cellular markers. In addition, kynurenine metabolism in the hippocampus was skewed toward the neurotoxic branch (151). Also, peripheral chronic, intermittent administration of LPS in laboratory animals resulted in depressive-like behaviors assessed by levels of anhedonia and despair. This was accompanied by hippocampal microglia activation and increased expression of IDO, increased levels of NF-kB p65 and IL-1 $\beta$ levels, elevated QUIN/tryptophan ratio, increased levels of kynurenine and QUIN, and decreased hippocampal levels of tryptophan, and 5-HT (152). Importantly kynurenine, besides being a precursor for TRYCATs, also 
has various immunomodulatory roles. For instance, it activates monocytes and astrocytes and is involved in the trafficking of monocytes to the brain, and those neuroimmune mechanisms are accompanied by depressive-like symptoms in laboratory animals (153). Above mentioned effects of kynurenine on monocyte chemotaxis take place with the involvement of the aryl hydrocarbon receptor (AhR). Moreover, kynurenine is involved in mast cell activation, also through AhR (154).

Numerous studies indicate the crucial role of kynurenine pathway activation in the pathogenesis of depressive disorders. For example, the interferon- $\alpha$ treatment of hepatitis $\mathrm{C}$ patients resulted in depressive symptoms along with changes in the kynurenine:tryptophan (KYN:TRP) concentration ratio and this ratio can indirectly characterize the activity of the enzymes of the IDO and TDO (155). Besides, the peripheral supply of interferon- $\alpha$ led to an increase in the concentration of KYN in cerebrospinal fluid (CSF) of patients, which was associated with a significant increase in the concentration of QUIN and KYNA in CSF. Also, the levels of these kynurenines correlated with the severity of depressive symptoms (156). Interestingly, it has been suggested that kynurenines may also play an important role in suicidal behavior. Post mortem study of severely depressed patients, who died due to suicide, demonstrated a significant upregulation of microglial QUIN in the anterior cingulate gyrus (18). Also, suicide attempters in the course of depression had a significantly increased level of QUIN but not KYNA in CSF (157). The CSF QUIN level was associated with higher CSF IL-6 levels, and QUIN correlated with suicidality. Moreover, MDD patients who attempted suicide had elevated KYN levels compared to MDD patients who did not have suicidal attempts (158). Another study demonstrated that adolescents with suicidal tendencies had a reduced level of TRP and an increased ratio of KYN:TRP (159).

\section{LPS and blood-brain-barrier}

Another essential aspect is the interaction of peripheral LPS with BBB. Crucial questions that call for the answer in this context are whether peripheral LPS can increase BBB permeability and whether $\mathrm{BBB}$ is penetrable for those bacterial antigens? And if so, does disruption of BBB integrity accompanies MDD?

Through decades the common consensus was that the CNS and particularly the brain is an immuneprivileged organ well protected by highly selective BBB. However, recent years of research revealed another side to it demonstrating that this barrier might be compromised by multiple factors, including psychological stress via (CRH)-mediated mast cell activation (160), bacterial LPS, O\&NS, proinflammatory cytokines (TNF- $\alpha$, IL-1 $\beta$, IFN- $\gamma$ ) and CCL11 (eotaxin) (90, 161-165). Interestingly, those factors also compromise the intestinal barrier. Additionally, intestinal microbiota modulate BBB permeability and short-chain fatty acids (SCFAs) produced by those bacteria, including butyrate and propionate, have a protective effect on BBB and decrease its permeability $(166,167)$. Furthermore, a 
relatively recent discovery that the central nervous system is equipped with the lymphatic system additionally advocates re-evaluation of the above consensus (168).

A respective number of in vivo animal studies demonstrated that peripheral LPS challenge results in disruption of BBB permeability (for review of the mechanisms see $(169,170)$ ). Varatharaj and Galea, in their systematic review, concluded that $60 \%$ of studies included in analysis revealed disrupted BBB after LPS challenge (169). Authors noted that variability in those results might be attributed to different LPS doses and dosing protocol used in studies, different species, age, health status, the gender of experimental animals, the time course of permeability estimation, and finally, types of solutes used as markers of BBB permeability. Vargas-Caraveo et al. were the first who revealed that LPS could penetrate BBB under physiological conditions and proposed mechanisms for that (171). The authors demonstrated the presence of two distinct LPS domains, namely, lipid A and core LPS in circumventricular organs, choroid plexus, meningeal cells, astrocytes, tanycytes, and endothelial cells and those domains were co-localized with CD14, TLR-4, and NF-kB. The results of the study also suggest that LPS crossed BBB via a lipoprotein-mediated transport mechanism.

Regarding human studies, so far, the field of neurodegenerative disorders, which are often comorbid with MDD, gives us the most compelling data indicating that translocation of LPS and other bacterial molecules via BBB is possible and, interestingly, this accounts for not only patients with dementia but also healthy individuals. There is a piece of strong evidence from post mortem studies of patients suffering from Alzheimer's disease, which demonstrated the increased LPS levels in grey and white matter compared to controls (172). Interestingly, LPS and Escherichia coli K99 pili protein were also present in the control group but in a much lower concentration. Moreover, E coli DNA was present in the brain tissues of patients and controls. This indicates that besides increased BBB to LPS in the course of the illness, highly likely, there are also physiological mechanisms of bacterial molecules translocation via BBB. Also, another study of brain lysates from patients with Alzheimer's disease demonstrated significantly higher LPS concentrations in the hippocampus and neocortex, which in the most severe case reached a 26-fold higher level compared to the control (173).

Regarding MDD, recently, it was demonstrated that depressed adolescents had a higher S100B serum level, and this parameter is considered as a marker of increased BBB permeability and is primarily expressed in astrocytes. Moreover, patients had a higher rate of serum food-specific IgG, and this was accompanied by increased serum levels of histamine and homocysteine (120). The authors of this study suggested that IgG-mediated type III hypersensitivity against food antigens could be the principal cause of increased histamine level, which in turn contributed to increased BBB permeability in depressed patients. It was also demonstrated in the course of bipolar disorder, that patients with increased BBB permeability had more significant symptoms of depression and anxiety and a more chronic course of the illness (174).

Still, it seems that the permeability of BBB in major depression is not a "black or white" scenario. Likely, it might vary depend on various factors, including genetic ones, the severity of the illness and 
the level, and the source of immune-inflammatory response accompanying the MDD and other. Moreover, the disruption of BBB is highly dependent on astrocyte function, and their abnormal function was reported in MDD. It also seems likely that interaction between peripheral inflammation, astrogliosis, and abnormal BBB permeability may progress in a vicious cycle manner where progressive dysfunction of those glial cells contributes to increased BBB permeability and subsequent, further neuroinflammatory changes contribute to astrocytic dysfunction and psychopathology.

\section{Lipoproteins - regulators of the peripheral endotoxin load}

As reviewed above, Vargas-Caraveo et al. suggested that LPS can cross BBB via lipoproteinmediated transport (171). When discussing the role of lipoproteins in the context of LPS transport, it is also important to point out lipoproteins' crucial homeostatic role in neutralizing LPS and their elimination in the liver $(175,176)$. For instance, high-density lipoprotein cholesterol (HDL-C) and its apolipoprotein A-I (ApoAI) have anti-inflammatory properties and high affinity to LPS and are involved in LPS neutralization, and transport to hepatocytes for their degradation. This mechanism prevents further LPS activation of inflammatory response and synthesis of pro-inflammatory cytokines $(171,177)$. Consequently, lipoproteins are one of the major determinants of LPS load in the circulation, and likely in CNS, and abnormal lipoproteins concentration may contribute to increased LPS-derived immune-inflammatory response both in the periphery and CNS. Interestingly, the connection between abnormal lipoproteins levels and MDD has been previously established. For instance, MDD patients had decreased HDL-C levels compared to controls, and patients with a history of serious suicide attempts had significantly lower HDL-C compared to MDD patients without such attempts (178-180). Moreover, patients with chronic depression had significantly lower HDL-C compared to healthy controls, or patients with shorter duration of depression $(181,182)$, and melancholic features of MDD were independently associated with lower HDL-C (180). The data above indicates an intriguing connection between increased intestinal permeability, adverse lipoprotein patterns, and depressive symptoms. Further exploration of this area might have implications for MDD treatment.

\section{LPS and glucocorticoids}

Another vital connection between LPS and depression is the involvement of endotoxin in glucocorticoid (GKK) functions and the immune response to those anti-inflammatory hormones. So far, there is compelling scientific data that suggests that LPS may contribute to GCC resistance what could also highly likely have a negative impact on intestinal barrier function. It is well established that hyperactivity of the HPA axis accompanies MDD, and 50\% to $80 \%$ of patients experience hypercortisolemia with the highest rates in severe depression (183), and the severity of depression correlates with cortisol plasma levels (119). Consistently, it was also proposed that the modulation of glucocorticoid receptors (GR) is one of the mechanisms involved in antidepressants' action (183). 
Furthermore, psychological stress and chronic inflammation are known to contribute to GCC resistance $(184,185)$. It was previously demonstrated, particularly in patients with Crohn's disease, that GCC treatment decreased intestinal permeability and retightened intestinal tight junctions (TJ) via inhibition of TNF- $\alpha$ - induced increase in myosin light chain kinase (MLCK) protein expression, and GCC beneficial influence on the intestinal barrier was mediated by GR $(186,187)$. Unfortunately, it is not uncommon that the longer time of GCC treatment, the less effective it is due to the gradual development of resistance to those anti-inflammatory hormones. Consequently, the deletion of intestinal epithelial GR receptor NR3C1 led to increased intestinal permeability (188). It was demonstrated that exposure to LPS increases the expression of GR $\beta$ in macrophage what contributed to GR resistance and inhibited the anti-inflammatory action of GCC $(189,190)$. Furthermore, LPS led to the loss of the GCC inhibitory effect on the secretion of granulocyte-macrophage colony-stimulating factor (GM-CSF) (191). However, the effect of LPS on expression of GR isoforms is not consistent and may vary depending on the cell types (191). Still, this seems an intriguing direction for further investigations whether the mechanism of GR resistance (due to i.e., LPS, pro-inflammatory cytokines, and cortisol) also contributes to intestinal GR resistance and subsequent increased intestinal permeability. This could, for example, take place due to the lack of GCC inhibitory role on TNF- $\alpha$ - induced increased intestinal permeability. Finally, it is worth mentioning that BBB is highly influenced by GCC, which decrease its permeability. There are many analogies between structure and functions of BBB and intestinal barrier, and both those barriers and their permeabilities are susceptible to analogous immune detrimental factors, including TNF- $\alpha$, IL-1 $\beta$, IFN- $\gamma$, O\&NS, and LPS.

\section{Increased intestinal permeability - the source of autoimmunity in MDD}

Another crucial aspect of how the "leaky-gut" may contribute to MDD, is the involvement of the compromised intestinal barrier in the autoimmunity (Fig.1). This is a very interesting and broad topic which introduction in-depth is beyond the scope of this chapter (for further reading see (25)). However, it is briefly worth mentioning that highly likely it is not an epidemiological coincidence that autoimmune disorders increase the risk of major depression and other psychiatric disorders $(192,193)$, and that there is growing evidence of increased intestinal permeability and dysbiosis in various autoimmune disorders, comorbid with MDD, such as IBD, MS, coeliac disease, diabetes, to name a few (96, 194-196). On the one hand, bacterial translocation leads to increased O\&NS, hypernitrosylation and generation of immunogenic neoepitopes (14). On the other hand, food-derived antigenic material, for instance, lectins and agglutynins, bind with the tissue and form neoepitopes in a covalent-binding mechanism what leads to autoimmunity. Another mechanism is a molecular mimicry/cross-reactivity, where due to unfortunate molecular coincidence, there is a structural homology between antigenic material (i.e., gut-derived or newly O\&NS/hypernitrosylation-formed) and own structure of the organisms what leads to the autoimmune reaction against this structure i.e., cell membrane, tissue etc. 
For instance, molecular mimicry between casein and butyrophilin with myelin, cerebellum or even a key enzymes responsible for GABA synthesis were demonstrated (197-200). Those fascinating, but concerning interactions clearly indicate to a substantial role of a healthy intestinal barrier, well balanced intestinal microbiota and a diet, in the context of inflammation, autoimmunity and mental health.

\section{Conclusions}

We are facing exciting times in neuroscience and psychiatry research and it is becoming evident that the mind-body connection takes place on the sites of interaction between the immune, endocrine, and nervous systems. Given that it is also becoming clear that a more holistic approach in the context of mental health diagnosis and treatment is required to warrant its truly efficient and long-term effects. Surely, the intestinal barrier with GALT and intestinal microbiota, which until quite recently remained the "forgotten organ" do play a major part in the above mind-body interactions. It is crucial to promote this knowledge among medical professionals and patients and to implement accessible and costeffective markers of intestinal permeability, gut-derived inflammation, and autoimmunities driven by bacterial and food-derived antigens. It is also important to bring more attention to the prophylactics and the treatment focusing on the improvement of the integrity of the intestinal barrier. This could include specific supplementation and dietary interventions with known benefits to the gut barrier, and those include, for example, probiotics, prebiotics, turmeric, zinc, glutamine and other. Diet is another crucial factor contributing to mental health and the field of nutritional psychiatry is recently receiving growing attention. A diet when is not well balanced i.e., Western, high-fat, high-carbohydrate diet, contributes to neuroinflammation and depression. Contrary, a good quality diet rich in antioxidants, polyphenols, fiber, pre and probiotics, healthy fats will have a therapeutic value. Making those healthy and conscious choices may be the first step towards wellbeing and a healthy body and mind. 
Figure 1. The Overview of mechanisms involved in increased intestinal permeability and subsequent activation of the immune-inflammatory response in depression

(Image generated using Servier Medical Art. Partially adapted and modified from Rudzki et al. 2012 (201))

1) Various factors contribute to increased intestinal permeability (i.e., psychological stress, inflammation, dysbiosis, O\&NS, diet and other); 2) Increased translocation of bacterial LPS through the intestinal epithelium and subsequent activation of the immune-inflammatory response (i.e., via activation of TLR4, RAGE, NF-kB) and increase levels of pro-inflammatory cytokines, O\&NS peripherally and within the CNS, LPS may contribute to the peripheral and within the CNS autoimmunity; 3) Increased translocation of food-derived antigens and formation of IgG immune complexes and IgG-mediated type III hypersensitivity; food antigens-associated molecular mimicry and covalent binding may lead to peripheral and within the CNS inflammatory response and autoimmunity); 4) Further disruption of the gut barrier due to released pro-inflammatory cytokines, O\&NS and activation of NF-kB; 5) Activation of IDO by LPS, pro-inflammatory cytokines, O\&NS with subsequent increased synthesis of TRYCATs and decreased availability of tryptophan for conversion to 5-HT and melatonin; 6) Detrimental influence of TRYCATs on the CNS; 7) Influence of pro-inflammatory cytokines and LPS on CNS by humoral route with subsequent: activation of HPA axis, increase expression of GR $\beta$ leading to GCC resistance; increase of BBB permeability, astrogliosis, microgliopathy, oligodendrocyte abnormalities, priming of glia, abnormalities in CNS TRYCATs, gliotransmitters and neurotropic factors, imbalance between GABA and glutamate and increased glutamate neurotransmission, abnormalities in 5-HT, NA and DA neurotransmission; 8) Peripheral LPS and pro-inflammatory cytokines activate the CNS inflammatory response via neural route (n.X); 9) Activation of HPA axis and subsequent increase in cortisol level; 10) Activation of TDO by elevated cortisol with subsequent increase in synthesis of TRYCATs and decreased availability of tryptophan for conversion to 5-HT and melatonin; 11) Further detrimental influence of TRYCATs on the CNS

BBB: blood-brain-barrier; BDNF: brain-derived neurotrophic factor; CNS: the central nervous system; CRH: corticotropin-releasing hormone; DA: dopamine; IgG: immunoglobulin G; GABA: $\gamma-$ aminobutyric acid; HPA: hypothalamic-pituitary-adrenal axis; GCC: glucocorticoids; GR $\beta$ : glucocorticoid receptor $\beta$; IDO: indoleamine 2,3 dioxygenase; LPS: bacterial lipopolysaccharides; LTRP: tryptophan; NA: noradrenaline; NF-кB: nuclear factor kappa B; NSAIDs: nonsteroidal antiinflammatory drugs; $n . X$ : vagal nerve; O\&NS: oxidative and nitrosative stress; RAGE: receptors for advanced glycation end products; SIBO: small intestinal bacterial overgrowth; SNS: the sympathetic nervous system; TLR: toll-like receptors; TRYCATs: tryptophan catabolites; 5-HT: serotonin 


\section{References}

1. Smith RS. The macrophage theory of depression. Med Hypotheses. 1991;35(4):298-306.

2. Maes M, Smith R, Simon S. The monocyte-T-lymphocyte hypothesis of major depression. Psychoneuroendocrinology. 1995;20(2):111-6.

3. Myint AM, Kim YK. Cytokine-serotonin interaction through IDO: a neurodegeneration hypothesis of depression. Med Hypotheses. 2003;61(5-6):519-25.

4. Maes M. The cytokine hypothesis of depression: inflammation, oxidative \& nitrosative stress (IO\&NS) and leaky gut as new targets for adjunctive treatments in depression. Neuro endocrinology letters. 2008;29(3):287-91.

5. Sanacora G, Treccani G, Popoli M. Towards a glutamate hypothesis of depression. Neuropharmacology. 2012;62(1):63-77.

6. Maes M, Kubera M, Leunis JC. The gut-brain barrier in major depression: intestinal mucosal dysfunction with an increased translocation of LPS from gram negative enterobacteria (leaky gut) plays a role in the inflammatory pathophysiology of depression. Neuro endocrinology letters. 2008;29(1):117-24.

7. Maes M, Kubera M, Leunis JC, Berk M. Increased IgA and IgM responses against gut commensals in chronic depression: further evidence for increased bacterial translocation or leaky gut. Journal of affective disorders. 2012;141(1):55-62.

8. Rial D, Lemos C, Pinheiro H, Duarte JM, Gonçalves FQ, Real Jl, et al. Depression as a GlialBased Synaptic Dysfunction. Frontiers in cellular neuroscience. 2016;9.

9. Maes M. Evidence for an immune response in major depression: a review and hypothesis. Progress in neuro-psychopharmacology \& biological psychiatry. 1995;19(1):11-38.

10. Maes M, Galecki P, Chang YS, Berk M. A review on the oxidative and nitrosative stress (O\&NS) pathways in major depression and their possible contribution to the (neuro)degenerative processes in that illness. Progress in neuro-psychopharmacology \& biological psychiatry. 2011;35(3):676-92.

11. Liu T, Zhong S, Liao X, Chen J, He T, Lai S, et al. A Meta-Analysis of Oxidative Stress Markers in Depression. PloS one. 2015;10(10):e0138904.

12. Maes M, Landucci Bonifacio K, Morelli NR, Vargas HO, Barbosa DS, Carvalho AF, et al. Major Differences in Neurooxidative and Neuronitrosative Stress Pathways Between Major Depressive Disorder and Types I and II Bipolar Disorder. Molecular Neurobiology. 2018.

13. Maes M, Moraes JB, Congio A, Bonifacio KL, Barbosa DS, Vargas HO, et al. Development of a Novel Staging Model for Affective Disorders Using Partial Least Squares Bootstrapping: Effects of Lipid-Associated Antioxidant Defenses and Neuro-Oxidative Stress. Molecular Neurobiology. 2019.

14. Maes M, Kubera M, Leunis JC, Berk M, Geffard M, Bosmans E. In depression, bacterial translocation may drive inflammatory responses, oxidative and nitrosative stress (O\&NS), and autoimmune responses directed against O\&NS-damaged neoepitopes. Acta psychiatrica Scandinavica. 2013;127(5):344-54.

15. Myint AM, Kim YK, Verkerk R, Scharpe S, Steinbusch H, Leonard B. Kynurenine pathway in major depression: evidence of impaired neuroprotection. Journal of affective disorders. 2007;98(12):143-51.

16. Maes M, Leonard BE, Myint AM, Kubera M, Verkerk R. The new '5-HT' hypothesis of depression: cell-mediated immune activation induces indoleamine 2,3-dioxygenase, which leads to lower plasma tryptophan and an increased synthesis of detrimental tryptophan catabolites (TRYCATs), both of which contribute to the onset of depression. Progress in neuropsychopharmacology \& biological psychiatry. 2011;35(3):702-21.

17. Myint AM, Schwarz MJ, Muller N. The role of the kynurenine metabolism in major depression. Journal of neural transmission (Vienna, Austria : 1996). 2012;119(2):245-51.

18. Steiner J, Walter M, Gos T, Guillemin GJ, Bernstein H-G, Sarnyai Z, et al. Severe depression is associated with increased microglial quinolinic acid in subregions of the anterior cingulate gyrus: 
Evidence for an immune-modulated glutamatergic neurotransmission? Journal of Neuroinflammation. 2011;8(1):94.

19. Shields GS, Slavich GM. Lifetime Stress Exposure and Health: A Review of Contemporary Assessment Methods and Biological Mechanisms. Soc Personal Psychol Compass.

2017;11(8):e12335.

20. Bierhaus A, Wolf J, Andrassy M, Rohleder N, Humpert PM, Petrov D, et al. A mechanism converting psychosocial stress into mononuclear cell activation. Proc Natl Acad Sci U S A. 2003;100(4):1920-5.

21. Munhoz CD, Lepsch LB, Kawamoto EM, Malta MB, Lima LdS, Werneck Avellar MC, et al. Chronic Unpredictable Stress Exacerbates Lipopolysaccharide-Induced Activation of Nuclear Factor$K B$ in the Frontal Cortex and Hippocampus via Glucocorticoid Secretion. The Journal of Neuroscience. 2006;26(14):3813-20.

22. Garate I, Garcia-Bueno B, Madrigal JL, Caso JR, Alou L, Gomez-Lus ML, et al. Stress-induced neuroinflammation: role of the Toll-like receptor-4 pathway. Biological psychiatry. 2013;73(1):32-43. 23. Bailey MT, Engler H, Powell ND, Padgett DA, Sheridan JF. Repeated social defeat increases the bactericidal activity of splenic macrophages through a Toll-like receptor-dependent pathway. 2007;293(3):R1180-R90.

24. Johnson JD, Campisi J, Sharkey CM, Kennedy SL, Nickerson M, Greenwood BN, et al. Catecholamines mediate stress-induced increases in peripheral and central inflammatory cytokines. Neuroscience. 2005;135(4):1295-307.

25. Rudzki L, Maes M. The Microbiota-gut-immune-glia (MGIG) Axis in Major Depression. Preprints. 2020;2020020084.

26. Vaure CL, Liu Y. A Comparative Review of Toll-Like Receptor 4 Expression and Functionality in Different Animal Species. Frontiers in Immunology. 2014;5.

27. Wang L, Wu J, Guo X, Huang X, Huang Q. RAGE Plays a Role in LPS-Induced NF-kB Activation and Endothelial Hyperpermeability. Sensors. 2017;17(4):722.

28. Soderholm JD, Perdue MH. Stress and gastrointestinal tract. II. Stress and intestinal barrier function. American journal of physiology Gastrointestinal and liver physiology. 2001;280(1):G7-g13. 29. Ferrier L. Significance of increased human colonic permeability in response to corticotrophin-releasing hormone (CRH). Gut. 2008;57(1):7-9.

30. Lambert GP. Stress-induced gastrointestinal barrier dysfunction and its inflammatory effects. Journal of animal science. 2009;87(14 Suppl):E101-8.

31. Keita AV, Soderholm JD. The intestinal barrier and its regulation by neuroimmune factors. Neurogastroenterology and motility : the official journal of the European Gastrointestinal Motility Society. 2010;22(7):718-33.

32. Vanuytsel T, van Wanrooy S, Vanheel H, Vanormelingen C, Verschueren S, Houben E, et al. Psychological stress and corticotropin-releasing hormone increase intestinal permeability in humans by a mast cell-dependent mechanism. Gut. 2014;63(8):1293-9.

33. De Punder K, Pruimboom L. Stress Induces Endotoxemia and Low-Grade Inflammation by Increasing Barrier Permeability. Frontiers in Immunology. 2015;6.

34. Zhang L, Song J, Bai T, Qian W, Hou X-H. Stress induces more serious barrier dysfunction in follicle-associated epithelium than villus epithelium involving mast cells and protease-activated receptor-2. Scientific reports. 2017;7(1).

35. Lange S, Delbro DS. Adrenoceptor-mediated modulation of Evans blue dye permeation of rat small intestine. Digestive diseases and sciences. 1995;40(12):2623-9.

36. Schäper J, Wagner A, Enigk F, Brell B, Mousa SA, Habazettl H, et al. Regional Sympathetic Blockade Attenuates Activation of Intestinal Macrophages and Reduces Gut Barrier Failure. 2013;118(1):134-42.

37. Beaurepaire C, Smyth D, McKay DM. Interferon-gamma regulation of intestinal epithelial permeability. J Interferon Cytokine Res. 2009;29(3):133-44. 
38. Schmitz H, Fromm M, Bentzel CJ, Scholz P, Detjen K, Mankertz J, et al. Tumor necrosis factoralpha (TNFalpha) regulates the epithelial barrier in the human intestinal cell line HT-29/B6. Journal of cell science. 1999;112 ( Pt 1):137-46.

39. Ye D, Ma I, Ma TY. Molecular mechanism of tumor necrosis factor-alpha modulation of intestinal epithelial tight junction barrier. American journal of physiology Gastrointestinal and liver physiology. 2006;290(3):G496-504.

40. Al-Sadi RM, Ma TY. IL-1beta causes an increase in intestinal epithelial tight junction permeability. Journal of immunology (Baltimore, Md : 1950). 2007;178(7):4641-9.

41. Chavez AM, Menconi MJ, Hodin RA, Fink MP. Cytokine-induced intestinal epithelial hyperpermeability: role of nitric oxide. Critical care medicine. 1999;27(10):2246-51.

42. Ma TY, Iwamoto GK, Hoa NT, Akotia V, Pedram A, Boivin MA, et al. TNF-alpha-induced increase in intestinal epithelial tight junction permeability requires NF-kappa $B$ activation. American journal of physiology Gastrointestinal and liver physiology. 2004;286(3):G367-76.

43. Bjarnason I, Peters TJ, Wise RJ. The leaky gut of alcoholism: possible route of entry for toxic compounds. Lancet (London, England). 1984;1(8370):179-82.

44. Bode C, Bode JC. Effect of alcohol consumption on the gut. Best practice \& research Clinical gastroenterology. 2003;17(4):575-92.

45. Leclercq S, Cani PD, Neyrinck AM, Starkel P, Jamar F, Mikolajczak M, et al. Role of intestinal permeability and inflammation in the biological and behavioral control of alcohol-dependent subjects. Brain, behavior, and immunity. 2012;26(6):911-8.

46. Leclercq S, Matamoros S, Cani PD, Neyrinck AM, Jamar F, Starkel P, et al. Intestinal permeability, gut-bacterial dysbiosis, and behavioral markers of alcohol-dependence severity. Proc Natl Acad Sci U S A. 2014;111(42):E4485-93.

47. Moreira APB, Texeira TFS, Ferreira AB, Do Carmo Gouveia Peluzio M, De Cássia Gonçalves Alfenas R. Influence of a high-fat diet on gut microbiota, intestinal permeability and metabolic endotoxaemia. British Journal of Nutrition. 2012;108(5):801-9.

48. Teixeira TF, Collado MC, Ferreira CL, Bressan J, Peluzio Mdo C. Potential mechanisms for the emerging link between obesity and increased intestinal permeability. Nutrition research (New York, NY). 2012;32(9):637-47.

49. Pan $\mathrm{P}$, Song Y, Du X, Bai L, Hua X, Xiao Y, et al. Intestinal barrier dysfunction following traumatic brain injury. Neurological Sciences. 2019;40(6):1105-10.

50. Lerner A, Matthias T. Changes in intestinal tight junction permeability associated with industrial food additives explain the rising incidence of autoimmune disease. Autoimmunity reviews. 2015;14(6):479-89.

51. Csáki KF. Synthetic surfactant food additives can cause intestinal barrier dysfunction. Medical Hypotheses. 2011;76(5):676-81.

52. Gillois K, Lévêque M, Théodorou V, Robert H, Mercier-Bonin M. Mucus: An Underestimated Gut Target for Environmental Pollutants and Food Additives. Microorganisms. 2018;6(2):53.

53. Samsel A, Seneff S. Glyphosate, pathways to modern diseases II: Celiac sprue and gluten intolerance. Interdisciplinary Toxicology. 2013;6(4):159-84.

54. Joly Condette $\mathrm{C}$, Khorsi-Cauet H, Morlière $\mathrm{P}$, Zabijak L, Reygner J, Bach V, et al. Increased Gut Permeability and Bacterial Translocation after Chronic Chlorpyrifos Exposure in Rats. 2014;9(7):e102217.

55. Defois C, Ratel J, Garrait G, Denis S, Le Goff O, Talvas J, et al. Food Chemicals Disrupt Human Gut Microbiota Activity And Impact Intestinal Homeostasis As Revealed By In Vitro Systems. Scientific reports. 2018;8(1).

56. Lambert GP. Intestinal barrier dysfunction, endotoxemia, and gastrointestinal symptoms: the 'canary in the coal mine' during exercise-heat stress? Medicine and sport science. 2008;53:61-73. 57. Pals KL, Chang RT, Ryan AJ, Gisolfi CV. Effect of running intensity on intestinal permeability. Journal of applied physiology (Bethesda, Md : 1985). 1997;82(2):571-6. 
58. Lambert GP, Gisolfi CV, Berg DJ, Moseley PL, Oberley LW, Kregel KC. Selected contribution: Hyperthermia-induced intestinal permeability and the role of oxidative and nitrosative stress. Journal of applied physiology (Bethesda, Md : 1985). 2002;92(4):1750-61; discussion 49.

59. Yamaguchi N, Sugita R, Miki A, Takemura N, Kawabata J, Watanabe J, et al. Gastrointestinal Candida colonisation promotes sensitisation against food antigens by affecting the mucosal barrier in mice. Gut. 2006;55(7):954-60.

60. Severance EG, Kannan G, Gressitt KL, Dickerson FB, Pletnikov MV, Yolken RH. Antibodies to food antigens: Translational research in psychiatric disorders. Neurology, Psychiatry and Brain Research. 2012;18(2):87-8.

61. van Ampting MT, Schonewille AJ, Vink C, Brummer RJ, van der Meer R, Bovee-Oudenhoven IM. Damage to the intestinal epithelial barrier by antibiotic pretreatment of salmonella-infected rats is lessened by dietary calcium or tannic acid. The Journal of nutrition. 2010;140(12):2167-72.

62. Ng KM, Ferreyra JA, Higginbottom SK, Lynch JB, Kashyap PC, Gopinath S, et al. Microbiotaliberated host sugars facilitate post-antibiotic expansion of enteric pathogens. Nature. 2013;502(7469):96-9.

63. Tulstrup MV-L, Christensen EG, Carvalho V, Linninge C, Ahrné S, Højberg O, et al. Antibiotic Treatment Affects Intestinal Permeability and Gut Microbial Composition in Wistar Rats Dependent on Antibiotic Class. PloS one. 2015;10(12):e0144854.

64. Becattini S, Taur Y, Pamer EG. Antibiotic-Induced Changes in the Intestinal Microbiota and Disease. Trends in molecular medicine. 2016;22(6):458-78.

65. Bjarnason I, Williams $P$, Smethurst $P$, Peters TJ, Levi AJ. Effect of non-steroidal antiinflammatory drugs and prostaglandins on the permeability of the human small intestine. Gut. 1986;27(11):1292-7.

66. Smetanka RD, Lambert GP, Murray R, Eddy D, Horn M, Gisolfi CV. Intestinal permeability in runners in the 1996 Chicago marathon. International journal of sport nutrition. 1999;9(4):426-33.

67. Fukui H. Increased Intestinal Permeability and Decreased Barrier Function: Does It Really Influence the Risk of Inflammation? Inflammatory Intestinal Diseases. 2016;1(3):135-45.

68. Wigg AJ, Roberts-Thomson IC, Dymock RB, McCarthy PJ, Grose RH, Cummins AG. The role of small intestinal bacterial overgrowth, intestinal permeability, endotoxaemia, and tumour necrosis factor alpha in the pathogenesis of non-alcoholic steatohepatitis. Gut. 2001;48(2):206-11.

69. Naseribafrouei A, Hestad K, Avershina E, Sekelja M, Linlokken A, Wilson R, et al. Correlation between the human fecal microbiota and depression. Neurogastroenterology and motility : the official journal of the European Gastrointestinal Motility Society. 2014;26(8):1155-62.

70. Jiang H, Ling Z, Zhang Y, Mao H, Ma Z, Yin Y, et al. Altered fecal microbiota composition in patients with major depressive disorder. Brain, behavior, and immunity. 2015;48:186-94.

71. Aizawa E, Tsuji H, Asahara T, Takahashi T, Teraishi T, Yoshida S, et al. Possible association of Bifidobacterium and Lactobacillus in the gut microbiota of patients with major depressive disorder. Journal of affective disorders. 2016;202:254-7.

72. Lin P, Ding B, Feng C, Yin S, Zhang T, Qi X, et al. Prevotella and Klebsiella proportions in fecal microbial communities are potential characteristic parameters for patients with major depressive disorder. Journal of affective disorders. 2017;207:300-4.

73. Cheung SG, Goldenthal AR, Uhlemann A-C, Mann JJ, Miller JM, Sublette ME. Systematic Review of Gut Microbiota and Major Depression. Frontiers in Psychiatry. 2019;10(34).

74. Giloteaux L, Goodrich JK, Walters WA, Levine SM, Ley RE, Hanson MR. Reduced diversity and altered composition of the gut microbiome in individuals with myalgic encephalomyelitis/chronic fatigue syndrome. Microbiome. 2016;4(1):30.

75. Nguyen TT, Kosciolek T, Eyler LT, Knight R, Jeste DV. Overview and systematic review of studies of microbiome in schizophrenia and bipolar disorder. Journal of psychiatric research. 2018;99:50-61.

76. Simeonova D, Stoyanov D, Leunis JC, Carvalho AF, Kubera M, Murdjeva M, et al. Increased Serum Immunoglobulin Responses to Gut Commensal Gram-Negative Bacteria in Unipolar Major 
Depression and Bipolar Disorder Type 1, Especially When Melancholia Is Present. Neurotoxicity Research. 2019.

77. Adams JB, Johansen LJ, Powell LD, Quig D, Rubin RA. Gastrointestinal flora and gastrointestinal status in children with autism--comparisons to typical children and correlation with autism severity. BMC gastroenterology. 2011;11:22.

78. De Angelis M, Francavilla R, Piccolo M, De Giacomo A, Gobbetti M. Autism spectrum disorders and intestinal microbiota. Gut microbes. 2015;6(3):207-13.

79. Tomova A, Husarova V, Lakatosova S, Bakos J, Vlkova B, Babinska K, et al. Gastrointestinal microbiota in children with autism in Slovakia. Physiology \& behavior. 2015;138:179-87.

80. Strati F, Cavalieri D, Albanese D, De Felice C, Donati C, Hayek J, et al. New evidences on the altered gut microbiota in autism spectrum disorders. Microbiome. 2017;5(1):24.

81. Williams BL, Hornig M, Buie T, Bauman ML, Cho Paik M, Wick I, et al. Impaired carbohydrate digestion and transport and mucosal dysbiosis in the intestines of children with autism and gastrointestinal disturbances. PloS one. 2011;6(9):e24585.

82. Bailey MT, Dowd SE, Galley JD, Hufnagle AR, Allen RG, Lyte M. Exposure to a social stressor alters the structure of the intestinal microbiota: implications for stressor-induced immunomodulation. Brain, behavior, and immunity. 2011;25(3):397-407.

83. Galley JD, Bailey MT. Impact of stressor exposure on the interplay between commensal microbiota and host inflammation. Gut microbes. 2014;5(3):390-6.

84. Maltz RM, Keirsey J, Kim SC, Mackos AR, Gharaibeh RZ, Moore CC, et al. Prolonged restraint stressor exposure in outbred CD-1 mice impacts microbiota, colonic inflammation, and short chain fatty acids. PloS one. 2018;13(5):e0196961.

85. Stevens BR, Goel R, Seungbum K, Richards EM, Holbert RC, Pepine CJ, et al. Increased human intestinal barrier permeability plasma biomarkers zonulin and FABP2 correlated with plasma LPS and altered gut microbiome in anxiety or depression. Gut. 2018;67(8):1555.2-7.

86. Calarge CA, Devaraj S, Shulman RJ. Gut permeability and depressive symptom severity in unmedicated adolescents. Journal of affective disorders. 2019;246:586-94.

87. Ohlsson L, Gustafsson A, Lavant E, Suneson K, Brundin L, Westrin A, et al. Leaky gut biomarkers in depression and suicidal behavior. 2019;139(2):185-93.

88. Severance EG, Alaedini A, Yang S, Halling M, Gressitt KL, Stallings CR, et al. Gastrointestinal inflammation and associated immune activation in schizophrenia. Schizophr Res. 2012;138(1):48-53. 89. Severance EG, Gressitt KL, Stallings CR, Origoni AE, Khushalani S, Leweke FM, et al. Discordant patterns of bacterial translocation markers and implications for innate immune imbalances in schizophrenia. Schizophr Res. 2013;148(1-3):130-7.

90. Maes M, Sirivichayakul S, Kanchanatawan B, Vodjani A. Breakdown of the Paracellular Tight and Adherens Junctions in the Gut and Blood Brain Barrier and Damage to the Vascular Barrier in Patients with Deficit Schizophrenia. Neurotox Res. 2019;36(2):306-22.

91. Maes M, Leunis JC. Normalization of leaky gut in chronic fatigue syndrome (CFS) is accompanied by a clinical improvement: effects of age, duration of illness and the translocation of LPS from gram-negative bacteria. Neuro endocrinology letters. 2008;29(6):902-10.

92. Maes M, Mihaylova I, Leunis JC. Increased serum IgA and IgM against LPS of enterobacteria in chronic fatigue syndrome (CFS): indication for the involvement of gram-negative enterobacteria in the etiology of CFS and for the presence of an increased gut-intestinal permeability. Journal of affective disorders. 2007;99(1-3):237-40.

93. D'Eufemia P, Celli M, Finocchiaro R, Pacifico L, Viozzi L, Zaccagnini M, et al. Abnormal intestinal permeability in children with autism. Acta paediatrica (Oslo, Norway : 1992). 1996;85(9):1076-9.

94. de Magistris L, Familiari V, Pascotto A, Sapone A, Frolli A, lardino P, et al. Alterations of the intestinal barrier in patients with autism spectrum disorders and in their first-degree relatives. Journal of pediatric gastroenterology and nutrition. 2010;51(4):418-24. 
95. Fasano A, Hill I. Serum Zonulin, Gut Permeability, and the Pathogenesis of Autism Spectrum Disorders: Cause, Effect, or an Epiphenomenon? The Journal of pediatrics. 2017;188:15-7.

96. Fasano A. Leaky gut and autoimmune diseases. Clinical reviews in allergy \& immunology. 2012;42(1):71-8.

97. Liu Z, Li N, Neu J. Tight junctions, leaky intestines, and pediatric diseases. Acta paediatrica (Oslo, Norway : 1992). 2005;94(4):386-93.

98. Addolorato G, Marsigli L, Capristo E, Caputo F, Dall'Aglio C, Baudanza P. Anxiety and depression: a common feature of health care seeking patients with irritable bowel syndrome and food allergy. Hepatogastroenterology. 1998;45(23):1559-64.

99. Jayashree B, Bibin YS, Prabhu D, Shanthirani CS, Gokulakrishnan K, Lakshmi BS, et al. Increased circulatory levels of lipopolysaccharide (LPS) and zonulin signify novel biomarkers of proinflammation in patients with type 2 diabetes. 2014;388(1-2):203-10.

100. Mathiisen TM, Lehre KP, Danbolt NC, Ottersen OP. The perivascular astroglial sheath provides a complete covering of the brain microvessels: An electron microscopic 3D reconstruction. Glia. 2010;58(9):1094-103.

101. Wang Q, Jie W, Liu JH, Yang JM, Gao TM. An astroglial basis of major depressive disorder? An overview. 2017;65(8):1227-50.

102. Cotter DR, Pariante CM, Everall IP. Glial cell abnormalities in major psychiatric disorders: the evidence and implications. Brain Research Bulletin. 2001;55(5):585-95.

103. Torres-Platas SG, Hercher C, Davoli MA, Maussion G, Labonté B, Turecki G, et al. Astrocytic Hypertrophy in Anterior Cingulate White Matter of Depressed Suicides. Neuropsychopharmacology. 2011;36(13):2650-8.

104. Mayhew J, Beart PM, Walker FR. Astrocyte and Microglial Control of Glutamatergic Signalling: A Primer on Understanding the Disruptive Role of Chronic Stress. Journal of Neuroendocrinology. 2015;27(6):498-506.

105. Li N, Zhang X, Dong H, Zhang S, Sun J, Qian Y. Lithium Ameliorates LPS-Induced Astrocytes Activation Partly via Inhibition of Toll-Like Receptor 4 Expression. Cellular Physiology and Biochemistry. 2016;38(2):714-25.

106. Liu GJ, Nagarajah R, Banati RB, Bennett MR. Glutamate induces directed chemotaxis of microglia. The European journal of neuroscience. 2009;29(6):1108-18.

107. Yirmiya R, Rimmerman N, Reshef R. Depression as a Microglial Disease. Trends in Neurosciences. 2015;38(10):637-58.

108. Torres-Platas SG, Cruceanu C, Chen GG, Turecki G, Mechawar N. Evidence for increased microglial priming and macrophage recruitment in the dorsal anterior cingulate white matter of depressed suicides. Brain, behavior, and immunity. 2014;42:50-9.

109. Ramirez K, Shea DT, McKim DB, Reader BF, Sheridan JF. Imipramine attenuates neuroinflammatory signaling and reverses stress-induced social avoidance. Brain, behavior, and immunity. 2015;46:212-20.

110. Tynan RJ, Weidenhofer J, Hinwood M, Cairns MJ, Day TA, Walker FR. A comparative examination of the anti-inflammatory effects of SSRI and SNRI antidepressants on LPS stimulated microglia. Brain, behavior, and immunity. 2012;26(3):469-79.

111. Dhami KS, Churchward MA, Baker GB, Todd KG. Fluoxetine and citalopram decrease microglial release of glutamate and D-serine to promote cortical neuronal viability following ischemic insult. Molecular and cellular neurosciences. 2013;56:365-74.

112. Wohleb ES. Neuron-Microglia Interactions in Mental Health Disorders: "For Better, and For Worse". Frontiers in Immunology. 2016;7.

113. Sokolov BP. Oligodendroglial abnormalities in schizophrenia, mood disorders and substance abuse. Comorbidity, shared traits, or molecular phenocopies? The international journal of neuropsychopharmacology. 2007;10(04):547. 
114. Tham MW, Woon PS, Sum MY, Lee T-S, Sim K. White matter abnormalities in major depression: Evidence from post-mortem, neuroimaging and genetic studies. Journal of affective disorders. 2011;132(1-2):26-36.

115. Sacchet MD, Gotlib IH. Myelination of the brain in Major Depressive Disorder: An in vivo quantitative magnetic resonance imaging study. Scientific reports. $2017 ; 7(1)$.

116. Sturgeon C, Fasano A. Zonulin, a regulator of epithelial and endothelial barrier functions, and its involvement in chronic inflammatory diseases. Tissue Barriers. 2016;4(4):e1251384.

117. Kéri S, Szabó C, Kelemen O. Expression of Toll-Like Receptors in peripheral blood mononuclear cells and response to cognitive-behavioral therapy in major depressive disorder. 2014;40:235-43.

118. Rudzki L, Frank M, Szulc A, Gałęcka M, Szachta P, Barwinek D. Od jelit do depresji - rola zaburzeń ciągłości bariery jelitowej i następcza aktywacja układu immunologicznego w zapalnej hipotezie depresji (Polish). From gut to depression - the role of intestinal barrier discontinuity and activation of the immune system in the depression inflammatory hypothesis. Neuropsychiatria $i$ Neuropsychologia/Neuropsychiatry and Neuropsychology. 2012;7(2):76-84.

119. Rudzki L, Pawlak D, Pawlak K, Waszkiewicz N, Malus A, Konarzewska B, et al. Immune suppression of IgG response against dairy proteins in major depression. BMC Psychiatry. 2017;17(1):268.

120. Tao R, Fu Z, Xiao L. Chronic Food Antigen-specific IgG-mediated Hypersensitivity Reaction as A Risk Factor for Adolescent Depressive Disorder. Genomics, Proteomics \& Bioinformatics. 2019.

121. Beutier H, Gillis CM, Iannascoli B, Godon O, England P, Sibilano R, et al. IgG subclasses determine pathways of anaphylaxis in mice. Journal of Allergy and Clinical Immunology.

2017;139(1):269-80.e7.

122. Karakula-Juchnowicz H, Gałęcka M, Rog J, Bartnicka A, Łukaszewicz Z, Krukow P, et al. The Food-Specific Serum IgG Reactivity in Major Depressive Disorder Patients, Irritable Bowel Syndrome Patients and Healthy Controls. Nutrients. 2018;10(5):548.

123. Reichenberg A, Yirmiya R, Schuld A, Kraus T, Haack M, Morag A, et al. Cytokine-associated emotional and cognitive disturbances in humans. Archives of general psychiatry. 2001;58(5):445-52. 124. Grigoleit JS, Kullmann JS, Wolf OT, Hammes F, Wegner A, Jablonowski S, et al. Dosedependent effects of endotoxin on neurobehavioral functions in humans. PloS one. 2011;6(12):e28330.

125. Sandiego CM, Gallezot J-D, Pittman B, Nabulsi N, Lim K, Lin S-F, et al. Imaging robust microglial activation after lipopolysaccharide administration in humans with PET.

2015;112(40):12468-73.

126. Furube E, Kawai S, Inagaki H, Takagi S, Miyata S. Brain Region-dependent Heterogeneity and Dose-dependent Difference in Transient Microglia Population Increase during Lipopolysaccharideinduced Inflammation. Scientific reports. 2018;8(1):2203.

127. Wang Y, Ni J, Zhai L, Gao C, Xie L, Zhao L, et al. Inhibition of activated astrocyte ameliorates lipopolysaccharide- induced depressive-like behaviors. Journal of affective disorders. 2019;242:52-9. 128. Rosenblat JD, Mclntyre RS. Efficacy and tolerability of minocycline for depression: A systematic review and meta-analysis of clinical trials. Journal of affective disorders. 2018;227:21925.

129. Henry CJ, Huang Y, Wynne A, Hanke M, Himler J, Bailey MT, et al. Minocycline attenuates lipopolysaccharide (LPS)-induced neuroinflammation, sickness behavior, and anhedonia. Journal of Neuroinflammation. 2008;5(1):15.

130. Pang Y, Cai Z, Rhodes PG. Disturbance of oligodendrocyte development, hypomyelination and white matter injury in the neonatal rat brain after intracerebral injection of lipopolysaccharide. Brain research Developmental brain research. 2003;140(2):205-14.

131. Jacob A, Hensley LK, Safratowich BD, Quigg RJ, Alexander JJ. The role of the complement cascade in endotoxin-induced septic encephalopathy. 2007;87(12):1186-94. 
132. Bodea LG, Wang Y, Linnartz-Gerlach B, Kopatz J, Sinkkonen L, Musgrove R, et al. Neurodegeneration by activation of the microglial complement-phagosome pathway. The Journal of neuroscience : the official journal of the Society for Neuroscience. 2014;34(25):8546-56.

133. Capuron L, Miller AH. Immune system to brain signaling: Neuropsychopharmacological implications. Pharmacology \& Therapeutics. 2011;130(2):226-38.

134. D'Mello C, Le T, Swain MG. Cerebral Microglia Recruit Monocytes into the Brain in Response to Tumor Necrosis Factor Signaling during Peripheral Organ Inflammation. 2009;29(7):2089-102.

135. Thomson CA, McColl A, Graham GJ, Cavanagh J. Sustained exposure to systemic endotoxin triggers chemokine induction in the brain followed by a rapid influx of leukocytes. J Neuroinflammation. 2020;17(1):94.

136. Chakravarty S. Toll-Like Receptor 4 on Nonhematopoietic Cells Sustains CNS Inflammation during Endotoxemia, Independent of Systemic Cytokines. 2005;25(7):1788-96.

137. Hung YY, Kang HY, Huang KW, Huang TL. Association between toll-like receptors expression and major depressive disorder. Psychiatry research. 2014;220(1-2):283-6.

138. Pandey GN, Rizavi HS, Ren X, Bhaumik R, Dwivedi Y. Toll-like receptors in the depressed and suicide brain. Journal of psychiatric research. 2014;53:62-8.

139. Lin FY, Chen YH, Tasi JS, Chen JW, Yang TL, Wang HJ, et al. Endotoxin Induces Toll-Like Receptor 4 Expression in Vascular Smooth Muscle Cells via NADPH Oxidase Activation and MitogenActivated Protein Kinase Signaling Pathways. 2006;26(12):2630-7.

140. Wang $P$, Han X, Mo B, Huang G, Wang C. LPS enhances TLR4 expression and IFNgamma production via the TLR4/IRAK/NFkappaB signaling pathway in rat pulmonary arterial smooth muscle cells. Molecular medicine reports. 2017;16(3):3111-6.

141. Gárate I, García-Bueno B, Madrigal JL, Bravo L, Berrocoso E, Caso JR, et al. Origin and consequences of brain Toll-like receptor 4 pathway stimulation in an experimental model of depression. 2011;8(1):151.

142. Hung Y-Y, Huang K-W, Kang H-Y, Huang GY-L, Huang T-L. Antidepressants normalize elevated Toll-like receptor profile in major depressive disorder. 2015.

143. Stone TW, Perkins MN. Quinolinic acid: a potent endogenous excitant at amino acid receptors in CNS. European journal of pharmacology. 1981;72(4):411-2.

144. Schwarcz R, Whetsell WO, Jr., Mangano RM. Quinolinic acid: an endogenous metabolite that produces axon-sparing lesions in rat brain. Science (New York, NY). 1983;219(4582):316-8.

145. Tavares RG, Tasca Cl, Santos CE, Alves LB, Porciuncula LO, Emanuelli T, et al. Quinolinic acid stimulates synaptosomal glutamate release and inhibits glutamate uptake into astrocytes. Neurochemistry international. 2002;40(7):621-7.

146. Stone TW, Darlington LG. Endogenous kynurenines as targets for drug discovery and development. Nature reviews Drug discovery. 2002;1(8):609-20.

147. Schwarcz R, Bruno JP, Muchowski PJ, Wu HQ. Kynurenines in the mammalian brain: when physiology meets pathology. Nature reviews Neuroscience. 2012;13(7):465-77.

148. Stone TW, Darlington LG. The kynurenine pathway as a therapeutic target in cognitive and neurodegenerative disorders. British journal of pharmacology. 2013;169(6):1211-27.

149. Forrest CM, Mackay GM, Oxford L, Millar K, Darlington LG, Higgins MJ, et al. Kynurenine metabolism predicts cognitive function in patients following cardiac bypass and thoracic surgery. Journal of neurochemistry. 2011;119(1):136-52.

150. Tan L, Yu JT, Tan L. The kynurenine pathway in neurodegenerative diseases: mechanistic and therapeutic considerations. Journal of the neurological sciences. 2012;323(1-2):1-8.

151. Parrott JM, Redus L, O'Connor JC. Kynurenine metabolic balance is disrupted in the hippocampus following peripheral lipopolysaccharide challenge. J Neuroinflammation. 2016;13(1):124.

152. Rodrigues FTS, de Souza MRM, Lima CNC, da Silva FER, Costa D, Dos Santos CC, et al. Major depression model induced by repeated and intermittent lipopolysaccharide administration: Long- 
lasting behavioral, neuroimmune and neuroprogressive alterations. Journal of psychiatric research. 2018;107:57-67.

153. Zang X, Zheng $X$, Hou $Y$, Hu M, Wang $H$, Bao X, et al. Regulation of proinflammatory monocyte activation by the kynurenine-AhR axis underlies immunometabolic control of depressive behavior in mice. The FASEB Journal. 2018;32(4):1944-56.

154. Kawasaki H, Chang HW, Tseng HC, Hsu SC, Yang SJ, Hung CH, et al. A tryptophan metabolite, kynurenine, promotes mast cell activation through aryl hydrocarbon receptor. Allergy. 2014;69(4):445-52.

155. Wichers MC, Koek GH, Robaeys G, Verkerk R, Scharpe S, Maes M. IDO and interferon-alphainduced depressive symptoms: a shift in hypothesis from tryptophan depletion to neurotoxicity. Molecular psychiatry. 2005;10(6):538-44.

156. Raison CL, Dantzer R, Kelley KW, Lawson MA, Woolwine BJ, Vogt G, et al. CSF concentrations of brain tryptophan and kynurenines during immune stimulation with IFN-alpha: relationship to CNS immune responses and depression. Molecular psychiatry. 2010;15(4):393-403.

157. Erhardt S, Lim CK, Linderholm KR, Janelidze S, Lindqvist D, Samuelsson M, et al. Connecting inflammation with glutamate agonism in suicidality. Neuropsychopharmacology. 2013;38(5):743-52. 158. Sublette ME, Galfalvy HC, Fuchs D, Lapidus M, Grunebaum MF, Oquendo MA, et al. Plasma kynurenine levels are elevated in suicide attempters with major depressive disorder. Brain, behavior, and immunity. 2011;25(6):1272-8.

159. Bradley KA, Case JA, Khan O, Ricart T, Hanna A, Alonso CM, et al. The role of the kynurenine pathway in suicidality in adolescent major depressive disorder. Psychiatry research. 2015;227(23):206-12.

160. Esposito P, Gheorghe D, Kandere K, Pang X, Connolly R, Jacobson S, et al. Acute stress increases permeability of the blood-brain-barrier through activation of brain mast cells. 2001;888(1):117-27.

161. Tsao N, Hsu HP, Wu CM, Liu CC, Lei HY. Tumour necrosis factor-alpha causes an increase in blood-brain barrier permeability during sepsis. Journal of medical microbiology. 2001;50(9):812-21. 162. Yang GY, Gong C, Qin Z, Liu XH, Lorris Betz A. Tumor necrosis factor alpha expression produces increased blood-brain barrier permeability following temporary focal cerebral ischemia in mice. Brain research Molecular brain research. 1999;69(1):135-43.

163. Wang W, Lv S, Zhou Y, Fu J, Li C, Liu P. Tumor necrosis factor-alpha affects blood-brain barrier permeability in acetaminophen-induced acute liver failure. European journal of gastroenterology \& hepatology. 2011;23(7):552-8.

164. Wong D, Dorovini-Zis K, Vincent SR. Cytokines, nitric oxide, and cGMP modulate the permeability of an in vitro model of the human blood-brain barrier. Experimental neurology. 2004;190(2):446-55.

165. Enciu AM, Gherghiceanu M, Popescu BO. Triggers and effectors of oxidative stress at bloodbrain barrier level: relevance for brain ageing and neurodegeneration. Oxid Med Cell Longev. 2013;2013:297512.

166. Braniste V, Al-Asmakh M, Kowal C, Anuar F, Abbaspour A, Tóth M, et al. The gut microbiota influences blood-brain barrier permeability in mice. Science translational medicine. 2014;6(263):263ra158-263ra158.

167. Hoyles L, Snelling T, Umlai U-K, Nicholson JK, Carding SR, Glen RC, et al. Microbiome-host systems interactions: protective effects of propionate upon the blood-brain barrier. Microbiome. 2018;6(1):55-.

168. Louveau A, Smirnov I, Keyes TJ, Eccles JD, Rouhani SJ, Peske JD, et al. Structural and functional features of central nervous system lymphatic vessels. Nature. 2015;523(7560):337-41.

169. Varatharaj A, Galea I. The blood-brain barrier in systemic inflammation. Brain, behavior, and immunity. 2017;60:1-12. 
170. Morris G, Fernandes BS, Puri BK, Walker AJ, Carvalho AF, Berk M. Leaky brain in neurological and psychiatric disorders: Drivers and consequences. Australian \& New Zealand Journal of Psychiatry. 2018;52(10):924-48.

171. Vargas-Caraveo A, Sayd A, Maus SR, Caso JR, Madrigal JLM, García-Bueno B, et al. Lipopolysaccharide enters the rat brain by a lipoprotein-mediated transport mechanism in physiological conditions. Scientific reports. 2017;7(1):13113.

172. Zhan X, Stamova B, Jin LW, DeCarli C, Phinney B, Sharp FR. Gram-negative bacterial molecules associate with Alzheimer disease pathology. Neurology. 2016;87(22):2324-32.

173. Zhao Y, Jaber V, Lukiw WJ. Secretory Products of the Human GI Tract Microbiome and Their Potential Impact on Alzheimer's Disease (AD): Detection of Lipopolysaccharide (LPS) in AD Hippocampus. Frontiers in cellular and infection microbiology. 2017;7:318.

174. Kamintsky L, Cairns KA, Veksler R, Bowen C, Beyea SD, Friedman A, et al. Blood-brain barrier imaging as a potential biomarker for bipolar disorder progression. Neurolmage: Clinical.

2019:102049.

175. Vreugdenhil ACE, Snoek AMP, Van 'T Veer C, Greve J-WM, Buurman WA. LPS-binding protein circulates in association with apoB-containing lipoproteins and enhances endotoxin-LDL/VLDL interaction. Journal of Clinical Investigation. 2001;107(2):225-34.

176. Yao Z, Mates JM, Cheplowitz AM, Hammer LP, Maiseyeu A, Phillips GS, et al. Blood-Borne Lipopolysaccharide Is Rapidly Eliminated by Liver Sinusoidal Endothelial Cells via High-Density Lipoprotein. 2016;197(6):2390-9.

177. Sumenkova DV, Polyakov LM, Panin LE. Apolipoprotein A-I as a Carrier of Lipopolysaccharide into Rat Hepatocytes. 2013;155(6):738-40.

178. Maes M, Smith R, Christophe A, Vandoolaeghe E, Gastel AV, Neels H, et al. Lower serum high-density lipoprotein cholesterol (HDL-C) in major depression and in depressed men with serious suicidal attempts: relationship with immune-inflammatory markers. Acta psychiatrica Scandinavica. 1997;95(3):212-21.

179. Huang T-L, Wu S-C, Chiang Y-S, Chen J-F. Correlation between serum lipid, lipoprotein concentrations and anxious state, depressive state or major depressive disorder. Psychiatry research. 2003;118(2):147-53.

180. van Reedt Dortland AK, Giltay EJ, van Veen T, van Pelt J, Zitman FG, Penninx BW. Associations between serum lipids and major depressive disorder: results from the Netherlands Study of Depression and Anxiety (NESDA). The Journal of clinical psychiatry. 2010;71(6):729-36. 181. Lehto SM, Hintikka J, Niskanen L, Tolmunen T, Koivumaa-Honkanen H, Honkalampi K, et al. Low HDL cholesterol associates with major depression in a sample with a 7-year history of depressive symptoms. Progress in Neuro-Psychopharmacology and Biological Psychiatry. 2008;32(6):1557-61.

182. Lehto SM, Niskanen L, Tolmunen T, Hintikka J, Viinamäki H, Heiskanen T, et al. Low serum HDL-cholesterol levels are associated with long symptom duration in patients with major depressive disorder. Psychiatry and Clinical Neurosciences. 2010;64(3):279-83.

183. Anacker C, Zunszain PA, Carvalho LA, Pariante CM. The glucocorticoid receptor: Pivot of depression and of antidepressant treatment? Psychoneuroendocrinology. 2011;36(3):415-25.

184. Quan N, Avitsur R, Stark JL, He L, Lai W, Dhabhar F, et al. Molecular mechanisms of glucocorticoid resistance in splenocytes of socially stressed male mice. Journal of Neuroimmunology. 2003;137(1):51-8.

185. Cohen S, Janicki-Deverts D, Doyle WJ, Miller GE, Frank E, Rabin BS, et al. Chronic stress, glucocorticoid receptor resistance, inflammation, and disease risk. Proc Natl Acad Sci U S A. 2012;109(16):5995-9.

186. Boivin MA, Ye D, Kennedy JC, Al-Sadi R, Shepela C, Ma TY. Mechanism of glucocorticoid regulation of the intestinal tight junction barrier. 2006;292(2):G590-G8. 
187. Fischer A, Gluth M, Weege F, Pape UF, Wiedenmann B, Baumgart DC, et al. Glucocorticoids regulate barrier function and claudin expression in intestinal epithelial cells via MKP-1.

2014;306(3):G218-G28.

188. Aranda CJ, Arredondo-Amador M, Ocón B, Lavín JL, Aransay AM, Martínez-Augustin O, et al. Intestinal epithelial deletion of the glucocorticoid receptor NR3C1 alters expression of inflammatory mediators and barrier function. The FASEB Journal. 2019;33(12):14067-82.

189. Haim YO, Unger ND, Souroujon MC, Mittelman M, Neumann D. Resistance of LPS-activated bone marrow derived macrophages to apoptosis mediated by dexamethasone. 2014;4.

190. Fernández-Bertolín L, Mullol J, Fuentes-Prado M, Roca-Ferrer J, Alobid I, Picado C, et al. Effect of Lipopolysaccharide on Glucocorticoid Receptor Function in Control Nasal Mucosa Fibroblasts and in Fibroblasts from Patients with Chronic Rhinosinusitis with Nasal Polyps and Asthma. PloS one. 2015;10(5):e0125443.

191. Molina ML, Guerrero J, Cidlowski JA, Gatica H, Goecke A. LPS regulates the expression of glucocorticoid receptor $\alpha$ and $\beta$ isoforms and induces a selective glucocorticoid resistance in vitro. J Inflamm (Lond). 2017;14:22-.

192. Benros ME, Waltoft BL, Nordentoft M, Krogh J, Mortensen PB. Autoimmunity and infections as risk factors for depression and other severe mental illnesses. Neurology, Psychiatry and Brain Research. 2012;18(2):40-1.

193. Benros ME, Waltoft BL, Nordentoft M, Østergaard SD, Eaton WW, Krogh J, et al. Autoimmune Diseases and Severe Infections as Risk Factors for Mood Disorders. JAMA psychiatry. 2013;70(8):812.

194. Fasano A. All disease begins in the (leaky) gut: role of zonulin-mediated gut permeability in the pathogenesis of some chronic inflammatory diseases. F1000Research. 2020;9:69.

195. Fasano A, Shea-Donohue T. Mechanisms of disease: the role of intestinal barrier function in the pathogenesis of gastrointestinal autoimmune diseases. Nature clinical practice Gastroenterology \& hepatology. 2005;2(9):416-22.

196. Opazo MC, Ortega-Rocha EM, Coronado-Arrázola I, Bonifaz LC, Boudin H, Neunlist M, et al. Intestinal Microbiota Influences Non-intestinal Related Autoimmune Diseases. Frontiers in Microbiology. 2018;9.

197. Vojdani A, Kharrazian D, Mukherjee P. The Prevalence of Antibodies against Wheat and Milk Proteins in Blood Donors and Their Contribution to Neuroimmune Reactivities. 2013;6(1):15-36.

198. Guggenmos J, Schubart AS, Ogg S, Andersson M, Olsson T, Mather IH, et al. Antibody CrossReactivity between Myelin Oligodendrocyte Glycoprotein and the Milk Protein Butyrophilin in Multiple Sclerosis. 2004;172(1):661-8.

199. Vojdani A, O'Bryan T, Green JA, McCandless J, Woeller KN, Vojdani E, et al. Immune response to dietary proteins, gliadin and cerebellar peptides in children with autism. Nutritional neuroscience. $2004 ; 7(3): 151-61$.

200. Stefferl A, Schubart A, Storch M, Amini A, Mather I, Lassmann H, et al. Butyrophilin, a Milk Protein, Modulates the Encephalitogenic T Cell Response to Myelin Oligodendrocyte Glycoprotein in Experimental Autoimmune Encephalomyelitis. 2000;165(5):2859-65.

201. Rudzki L, Frank M, Szulc A, Gałęcka M, Szachta P, Barwinek D. From gut to depression - the role of intestinal barrier dysfunction and activation of immune system in inflammatory hypothesis of depression. Neuropsychiatria i Neuropsychologia 2012;7(2):76-84. 